\title{
Success of an interdisciplinary educational program on nursing knowledge about epidural analgesia in a critical care setting
}

\author{
ME O'Connor ${ }^{1}$, T Livingstone ${ }^{2 *}$, M Healy ${ }^{2}$, A Beane $^{2}$ \\ From ESICM LIVES 2015 \\ Berlin, Germany. 3-7 October 2015
}

\section{Introduction}

Nursing education is a key component to the delivery of safe epidural analgesia in the post-operative critical care setting [1].

An audit of our practice revealed a significant failure rate in epidural analgesia in elective major abdominal surgery patients and a high proportion of missing documentation in cases where epidural analgesia had failed.

\section{Objectives}

To devise and deliver an interdisciplinary education program to enhance nursing knowledge and management of epidural analgesia in critical care patients.

To improve patient safety through earlier recognition of adverse events by encouraging improved monitoring of epidural analgesia.

\section{Methods}

We developed a teaching program for nursing staff on the care of patients receiving epidural analgesia.

The program consisted of a lecture course and interactive teaching session with a pre course questionnaire to assess existing knowledge of the benefits and complications of epidural analgesia and management of common side effects. We repeated the questionnaire after the course without the participants having prior knowledge that this would occur.

\section{Results}

The group of 36 nurses who participated had been qualified for a median of 5 years IQR $(3,10)$, they had worked in a critical care environment for a median of 2.5 years
IQR $(1,5.25)$ and $25 \%$ of them had some experience of managing epidural analgesia in an environment outside of critical care.

Following the education program there was 56\% increase in the number of nurses who could identify at least two advantages of epidural analgesia for patients who had undergone major abdominal surgery.

There was a $26 \%$ improvement in the number of nurses able to identify signs of high sensory level blockade, $47 \%$ improvement in the number of nurses able to name methods for improving an inadequate block and a $67 \%$ improvement in the number of nursing staff being able to identify signs of a potential epidural haematoma.

\section{Conclusions}

Baseline nursing knowledge of clinical assessment and recognition of associated complications of epidural analgesia was limited despite a pre-existing trust-wide education program.

Interdisciplinary training is beneficial to the acquisition of short-term knowledge with regard to optimising effective pain relief and identifying common side effects.

The post course short answer exam highlights a significant increase in nursing awareness of potential serious complications of epidural analgesia.

We expect that increased nursing knowledge of the benefits of epidural analgesia and its potential problems will lead to comprehensive monitoring, superior post-operative analgesia and a reduction in adverse events. 


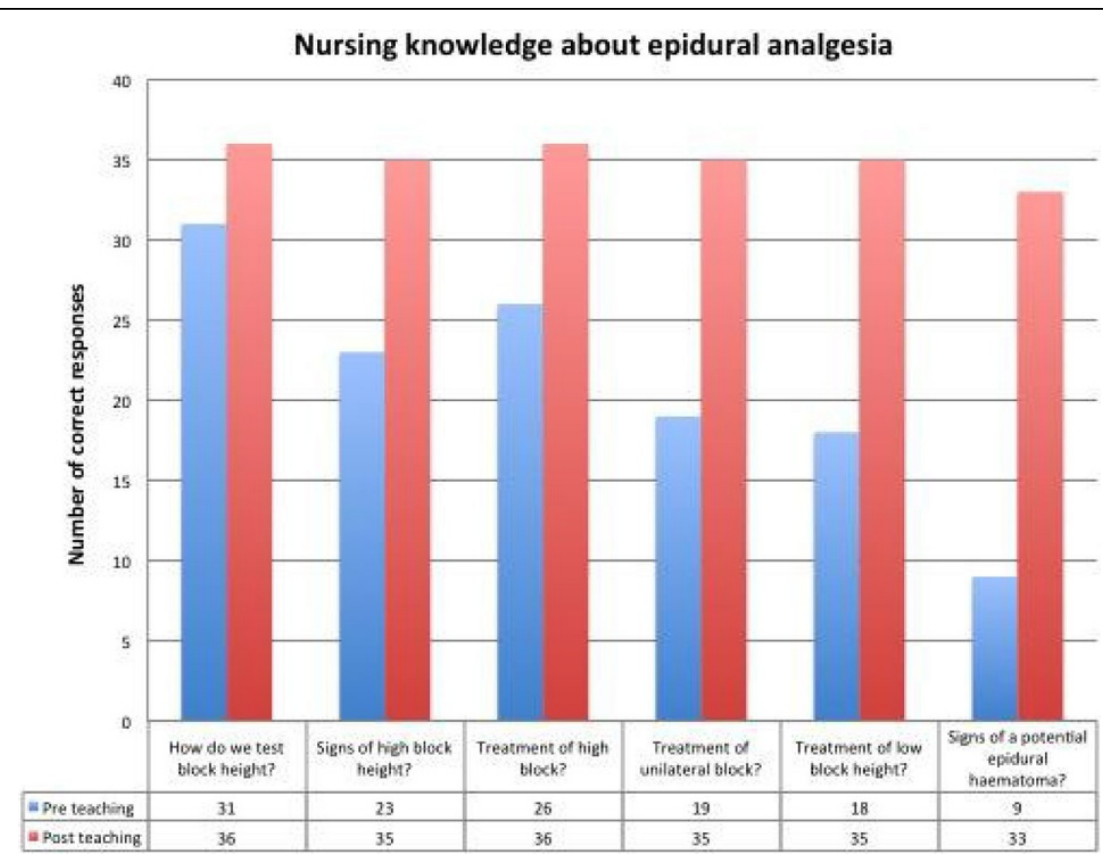

Figure 1 Nursing Knowledge About Epidural Analgesia.

\section{Authors' details}

${ }^{1}$ Barts Health NHS Trust, ACCU, London, United Kingdom. ${ }^{2}$ Barts Health NHS

Trust, London, United Kingdom.

Published: 1 October 2015

\section{Reference}

1. The $3^{\text {rd }}$ National audit project of the royal college of anaesthetists.

Major complications of central neuroaxial block in the United Kingdom. RCOA, London 2009.

doi:10.1186/2197-425X-3-S1-A928

Cite this article as: $\mathrm{O}^{\prime}$ Connor et al:: Success of an interdisciplinary

educational program on nursing knowledge about epidural analgesia in a critical care setting. Intensive Care Medicine Experimental 2015 3(Suppl 1): A928.

\section{Submit your manuscript to a SpringerOpen ${ }^{\odot}$ journal and benefit from:}

- Convenient online submission

- Rigorous peer review

- Immediate publication on acceptance

- Open access: articles freely available online

- High visibility within the field

- Retaining the copyright to your article 